\title{
Interactive comment on "Retrieval of ice nucleating particle concentrations from lidar observations: Comparison with airborne in-situ measurements from UAVs" by Eleni Marinou et al.
}

\section{Eleni Marinou et al.}

elmarinou@noa.gr

Received and published: 29 May 2019

The comment was uploaded in the form of a supplement:

https://www.atmos-chem-phys-discuss.net/acp-2018-1203/acp-2018-1203-AC1-

supplement.pdf

Interactive comment on Atmos. Chem. Phys. Discuss., https://doi.org/10.5194/acp-2018-1203, 